\title{
The Reformation Process in Ukrainian Higher Education Institutions According to the Credit-Module System: Evaluation by Lecturers and Students
}

\author{
Valery V. Burega ${ }^{1}$, Oksana K. Mikheyeva ${ }^{1}$, Irina N. Sikorskaya ${ }^{1}{ }^{*}$ \\ ${ }^{1}$ Donetsk State University of Management, 163a Cheljuskintsev, 83015 Donetsk, Ukraine
}

KEYWORDS

Higher education University reform Human factor

\section{ABSTRACT}

The article presents a general evaluation of the higher education system under reform in Ukraine with examples of some higher education institutions in different regions, and demonstrates basic tendencies and regularities which typical of all the institutions that are undergoing similar processes of reform. The process is heavily influenced by the so-called "human factor", by investigating the participants' opinion. The empirical data presented in this paper demonstrate how lecturers and students understand the reform process in different ways.

\section{Introduction}

Ukraine has inherited a well-built, comprehensive higher education system from the soviet regime. Since its independence in 1991, one of the top priorities of the young state has been to diminish the Russian influence in public life and to promote the Ukrainian language and culture. However, today the processes of globalization and integration force government to search for ways of reforming the education system by addressing the needs of local, regional, national, and international labour markets.

The transfer from elite to mass education, which occurred in the end of the $20^{\text {th }}$ century dramatically, changed the nature of education services in many countries. It brought new questions to the agenda, including of how to ensure that teaching quality remained high in big classes (Eco 2004), that of mass access to higher education, of the devaluation of the diploma as a

* Contact address: intdep@dsum.edu.ua (Irina Sikorskaya) 
guarantee of successful employment and the effect this would have on students gaining a higher social position (Beck 2005). From Ulrich Bech's point of view, present-day secondary school and secondary vocational education do not provide their graduates with a chance for professional selfrealization, and higher education continues to lose its role in providing graduates with guarantees of employment because there are too many specialists with diplomas in the labour market, and because intensive changes in the demands of society devalue the acquired knowledge very quickly. This fact is taken into account by the American scholar Manuel Castells (2000), who thinks that today only those who follow the model of life-long learning after being awarded diplomas can continue to develop their professional perspectives. The famous German specialist Jurgen Habermas (1987) considers education as an assurance of freedom and personal development, and the ability to form his/her own civil position. The works of the French sociologist Pierre Bourdieu (1967) attract our attention by the idea of connecting the system of education with the system of thinking and by considering them to be interrelated. One of the landmarks relating to the beginning of changes in education sphere was the work of Robert Barr and John Tagg (1995), in which the authors declared the need for education reform, and offered the new frameworks for an educational process.

In Ukraine, similar problems in the educational system have become very topical and the following conceptual issues are under consideration: the impact of the formation of a knowledge-based society on the transformation processes in the education system (Bakirov 2006), practical questions in realizing the reforms, equal access to higher education for all, quality assurance, the theory and practice of monitoring the educational reforms (Mikheyeva and Burego 2008).

In the work of Western European researchers, we can find reflections of those problems which are typical for all the actors in the globalized educational system: devaluation of diplomas, mass character of education, a lowering of the quality of education, the weakness of the practical component in training, etc. All the above mentioned factors have become an impulse for scientific investigation and a search for new ways of organizing the educational system which will meet the requirements of the modern age 
and allow for the preparation of specialists who can satisfy society's demands.

The Bologna Declaration (1999) appeared to be a starting point for unifying higher education in the European Higher Education Area (EHEA), where dynamic integration processes have occurred.

Ukraine signed the Bologna declaration in 2005. Since then Ukraine has treated itself as a member of the EHEA and has been striving to accomplish reforms of the educational system in general and of higher education in particular.

It should be emphasized that the reformation process is greatly influenced by the so-called "human factor", and relies heavily on the participants' opinion. The process of reform is not easy. The traditional schemes and frameworks of the educational process, teaching tools and the student-lecturer communication are under careful and systematic adjustment. And because of this, for the administration of each higher education institution it is very useful to conduct continuous, well-organized, purposeful, and systematic observation of the actual state of the reform process, in other words - monitoring the lecturers and the students' attitudes to the reform.

This precise factor has served as a basis for conducting an annual polling of lecturers and students of Donetsk State University of Management to discover their attitude towards the main elements of the Credit-Module System.

The practice of conducting a survey of the reform has taken place annually since 2004 . This practice appeared to be successful and the same questionnaire form was used to conduct the survey in public universities which provide business-management education in Central and Eastern Ukraine, where Donetsk State University of Management is located. In 2008, it was clearly demonstrated that the process of reform in the chosen universities was approximately at the same level, with minor variations related to the administrative policy of a particular institution.

The aim of this research was to evaluate the state of higher education both in Donetsk region and in some other Ukrainian higher education institutions (HEIs); to reveal basic tendencies and trends that were typical in all institutions which experience similar reform processes; to create a data 
base for correcting the process; to forecast possible paths of development and to elaborate concrete management activities; as well as to inform society in general about the state and development of higher education in Ukraine. The methodology can also be used as a template for individual higher education institutions wishing to carry out an internal diagnosis.

It is necessary to make some remarks before examining the data obtained. In this case we deal with some issues which are difficult to compare - an average person's perception of the situation, his/her expectations and hopes. That is why the information given in the research does not reveal a real state of the reform in Ukrainian higher educational institutions, but rather demonstrates lecturers' and students' attitudes towards the Credit Module System (CMS) and the application of certain of its elements in different HEIs.

Naturally, personal attitude and evaluation depend on a person's general mood, internal atmosphere in a higher educational intuition, level of corporate culture development, vision of development prospects, welfare standards, self-actualization etc. So, the data obtained are rather the indicators of perception or non-perception of the reformation processes and cannot be regarded as a basis for assessing leading and developing higher educational institutions without additional analysis of the formal indicators of their development, such as: quality of teaching staff, ratio of doctors of science, candidates of science and lecturers without scientific degree; average age of lecturers; the number of students participating in foreign study programs; the number of international agreements; numbers of foreign guest lecturers invited per year.

The survey was dedicated to studying the level of acceptance by teachers and students of the main elements of Credit-Module System (CMS), their evaluation of the reformation process in HEIs, the depth and the essence of the reform processes. The opinion poll comprised of 826 individuals from seven universities, among them: 205 lecturers and 621 students. The sampling was performed by bimodal random selection of the individuals: higher education institutions, lecturers and students. The general totality comprised higher education institutions located in Eastern and Central Ukraine. At the first stage the HEIs were defined by random selection. At the second stage - in each HEI four students groups and three 
departments were selected. In the selected units the complete survey was conducted. The questioning was conducted according to the signed agreements with the selected universities.

\section{The general evaluation of CMS by students and lecturers}

The empirical data presented here demonstrate a positive dynamics of perception of this process by lecturers and students. The opinions about the introduced Credit-Module System among the participants of the poll were represented in the following ways:

$23.7 \%$ of students are completely satisfied with the new system;

$50.45 \%$ of students are partially satisfied.

These two groups together count for $74.2 \%$ of all the interviewed persons - in fact these are the students who have accepted the new education system and they do not want to return to the previous one. Students who are not ready for the new organization of the education process embrace $25.8 \%$.

As far as lecturers are concerned the figures are presented in the following way:

$22 \%$ of lecturers are completely satisfied with the introduced CMS;

$52 \%$ of lecturers are partially satisfied.

Along with that $26 \%$ of lecturers would like to return to the previous education system.

The majority of the participants has recognized and accepted the new education model and they are ready to follow its requirements, norms, and instructions. Most of the elements of the CMS are positively approved. Thus we can state that the reform has passed the point of no-return. However it should be pointed out that almost a quarter of the interviewed individuals among lecturers and students are those who would like to return to the previous educational model. This group requires additional attention so that the reformation process can be more effective.

As far as the acceptance of the separate elements of the CMS is concerned it should be pointed out that $47.9 \%$ of students consider "individualization of the education process" as an advantage; $23.5 \%$ of them regard positively "the increased amount of independent work"; $49 \%$ like 
"introduction of individual classes". These elements are in the so-called "risk zone" and require special attention as well.

The occurrence of these very elements of the Credit-Module System in the risk zone is not occasional. During the reformation period, the Ukrainian system of higher education has gradually got rid of its collectivistic features and has been reoriented from a paradigm of teaching to a paradigm of learning. This transfer has changed the function of a lecturer, who ceased to be a translator of knowledge and an information carrier but is now a specialist who creates the appropriate environment in which a student can become not an object of training, but an active subject, willing to search and acquire professionally-orientated knowledge. It is evident that students are not satisfied with these particular elements of CMS because most of them are not used to exercising personal responsibility for their learning outcomes and have no experience of independent work.

Concerning lecturers' evaluation the following elements have occurred in the risk zone: only $19.6 \%$ of the interviewed individuals consider "reducing of contact hours" as an advantage; $47.3 \%$ of them consider "cancelling the examinations" as a positive sign; $47.85 \%$ of lecturers view "written forms of knowledge control" as a "plus".

Mostly the lecturers' negative attitudes to the reducing of contact hours are due to their worries about the quality assurance caused by the deficit of students' ability to carry out independent work. As well as this, the lecturers' workload has strikingly increased (testing essays, tests, individual assignments, etc). And this work is unpaid.

The fact that almost $50 \%$ of lecturers do not approve of CMS as a "way of refusing exams as a form of final knowledge control" and not as an "additional opportunity to improve an average grade obtained by a student during a semester" reflects the continuing discussion about the role and the purpose of mid-term examinations.

The autonomy granted to some Ukrainian universities created a situation whereby they have rejected exams as a form of final knowledge control, and only take account of the grades the students gain during each semester. Other HEIs consider exams as one part of the total grade obtained by a student according to the results of semester studies (moreover, in different universities and within different disciplines there are different 
opinions as to what the percentage of an exam grade is within a total grade). This leads to misunderstandings among lecturers and students (as we can see in survey, $20 \%$ of students and $60 \%$ of lecturers consider the lack of unified requirements a real problem).

A majority of students accept the following CSM elements: "recognition of study results in Ukraine and abroad" (86.7\%), "new forms of organization of education process" (82.5\%), "interactive methods of teaching" (81.9\%), and "refusing mid-term exams" (81.1\%).

Lecturers regard the following CMS elements as the most positive advantages: "interactive methods of teaching" (89.7\%), "new forms of organization of education process" (87.2\%), "systematic character of knowledge control" (86.3\%), "active partner interaction between studentteacher" (82\%), "recognition of study results in Ukraine and abroad" $(81.9 \%)$, and a "variety of knowledge control methods" (81\%).

Thus, we can see that students and lecturers view changes in the methods of teaching positively, and reject the pseudo-academic approach (sight-read lectures and sight-read answers at seminars; formalistic approach to educational process, etc.). Such characteristics as innovative approach, creativeness, and the creation of a learning atmosphere in the classroom are needed not only by lecturers, but also by students and they come up to their expectations in full measure.

However, there are some CMS elements which are evaluated by students and lecturers in radically different ways. First of all, with reference to the students' and lecturers' attitude towards the increase of independent learning: the survey shows that $68 \%$ of lecturers see this as a positive element, whereas $69.9 \%$ of polled students consider it as a disadvantage.

Lecturers also evaluate highly such elements as: individualization of training, introducing individual classes as a new form of educational process, increasing the competition among students, and systematic character of knowledge control. Students demonstrate less approval of these elements of CMS. This students' reaction can be explained by their lack of experience in doing systematic work, the lack of a reliable attitude to studies and also by the necessity of adapting to a new, more transparent and systematic form of knowledge control. The data prove that the students are not ready to work independently, they prefer to obtain a complete "learning 
product" from lecturers in class, and they wish to avoid personal responsibility for the quality of education.

We see the difference of lecturers' and students' opinions related to mid-term exanimations as a final control. The majority of students (almost $81.1 \%$ ) admit "refusal of exams" as an advantage. Lecturers' opinions are presented in the following way: $47.3 \%$ evaluate it positively, $49.3 \%$ negatively. Thus, we observe compared to students, lecturers do not agree about exams and their role in the education process, and this leads to the divergence of evaluation schemes both at the level of HEIs and at the level of lecturers' opinions.

\section{The rating of main problems to be solved in HEIs under the terms of implementing Credit-Module System according to lecturers and students' opinions}

Lecturers and students were offered a choice from the list of the problems which they consider to be the most important. As a result it became possible to build a general rating of the problems (by the frequency of their occurrence) which are essential both for lecturers and students and for proposing an appropriate rating for each particular university.

The main problem within the new education scheme was "superficial learning of subjects due to the excessive intensity of the education process" (51.9\% students highlighted this problem) and it correlates with student's dislike of independent work and lecturers' worries about "students' lack of self-work skills " (this problem occupies the first place in the lecturers' poll, $77.6 \%)$.

Students and lecturers emphasized the following weaknesses:

- The lack of information about objectives, tasks and main issues of CMS (36.1\%),

- The lack of adequate material and technical support for lessons: hand-outs, electronic resources, and technical support facilities (34.1\%),

- The lack of manuals and methodical materials for independent study $(32 \%)$.

Students are less worried about their low motivation to study alone, the excess of information, or their lack of skills in self-work. In general, 
students are more inclined to search external sources for their study problems rather than to blame their low inner motivation.

According to lecturers' poll the main problems of introducing CMS are placed in the following order:

- The lack of students' skills of self-work (this problem was pointed out by $77.6 \%$ ),

- The lack of contact hours for more thorough study of subject (62\%),

- The superficial study of subject due to the intensity of the education process $(53.6 \%)$.

Lecturers (32.4\%) also agree with the students that "the lack of adequate material and technical support for lessons: hand-outs, electronic resources, and technical facilities can cause a problem because lecturers and students relate to each other interactively and each player understands how technical support could intensify the education process and make it better.

Lecturers could feel a growing bureaucracy at HEIs (shown in the increase of controlling forms, reports, instructions, etc.). We consider this as a specific result of the attempt to unify the higher education system which is impossible without detailed research of the state and dynamics of the development of its principal elements. This certainly leads to an increase of paper work. It can also be a form of internal self-defence of a system which is in transition. As a result, instead of becoming more flexible the transitional system is trying to preserve itself by increasing bureaucracy.

\section{Lecturers' and students' evaluation of the first results of reform of higher education in Ukraine connected with the external recognition of a higher education institution and its activities}

In the questionnaire, lecturers and students were asked to evaluate the first results of reform of higher education in Ukraine, with reference to the external recognition of their institutions, such as: recognition of Ukrainian national diplomas in European countries, increasing students' mobility, successful employment of graduates in the national and international labour markets, inviting foreign guest lecturers, intensive studying of foreign languages, participation of lecturers and students in joint international research projects, active work of the international relations offices, students and lecturer's exchange programs with partner institutions. 
The number of those who noticed the changes was smaller than those who consider that no changes were made at all. Several people did not give any answer.

Both in lecturers' and students' opinions, one of the most attractive trends of the reform is the possibility of participating in international activities: $57.4 \%$ of polled students and $47.8 \%$ of lecturers consider that this fact has become a reality in the present higher education system of higher education. The lecturers showed more doubts about the "expansion of students' mobility in the framework of the European Higher Educational Area": only $18.1 \%$ of the polled lecturers believed this was possible. Students identify the potential possibilities in this relation more positively: $33.2 \%$ of them confirmed that it has already taken place.

Lecturers' and students' evaluation of "the recognition of the national educational system in Europe due to the standardization of assessment criteria and their mutual recognition" was more vigilant. It was confirmed by $25.2 \%$ of lecturers and by $37.5 \%$ of students.

In general, lecturers tend to be more cautious when evaluating the changes in organizing the education process and the new opportunities students face today. Lecturers are more optimistic when assessing the increasing employment opportunities for graduates: $38.3 \%$ of lecturers and $34.3 \%$ of students consider it as a reality.

In general, we can notice that the reform has gradually embraced all the elements of the educational process. The evidence of changes is confirmed by $35-45 \%$ of lecturers and students that makes more than one third of all polled participants.

\section{Conclusions}

Having examined the process of introducing the Credit-Module System by interviewing lecturers and students in several higher education institutions of Central and Eastern Ukraine we obtained a fairly general picture of the perception and evaluation of reform processes by the actual participants. The most general result of the research is that the majority of the persons polled, both students and lecturers, accepted the new system and are ready to work in concordance to its requirements, norms and 
settings. Most elements of CMS have been approved and accepted by the polled participants.

According to the students' and lecturers' evaluation, the reform's most striking achievement is the introduction of interactive teaching methods, and of various forms of knowledge control. Another benefit is that almost one third of the polled individuals believed that the reforms enabled lecturers and students to participate more widely in exchange programs, increased the students' mobility, enabled graduates to compete successfully in national and international labour markets, and allowed lecturers and students to participate in joint international research projects.

In spite of the general acceptance of the reform and its particular directives we need to draw attention to a set of problems faced by the Ukrainian higher education system and which are of concern to the main participants in its reform - lecturers and students. An important issue is the decreasing quality of education. In accordance with the conceptual purposes of the reform, the quality of education should become higher due to the introduction of individual training, interactive teaching methods, increasing the students' reliance on their own independent work. All these introductions are expected to produce a specialist capable of operating in a knowledge-based economy. However certain drawbacks related to the introduction of these new forms of organization show that students accumulate grades mechanically and acquire only fragmentary knowledge. We assume that the way out of this situation lies in strengthening attention to students' independent learning skills and sharing responsibility for learning outcomes with their lecturers. This can be done by preparing methodical materials and manuals which are suited to each individual student.

Based on the data obtained in the survey it should be pointed out that a majority of lecturers and students express satisfaction with the reform of their HEIs. The external indicators of the HEIs functioning depend mainly on the political (relations of Ukraine with EU) and economical (financial support of mobility) situation in the country.

Thus the higher education reform process in Ukraine insists on a systematic and complex approach to the above-mentioned problems which could lead to the increasing quality of education at all levels, and provision 
of all the necessary support for the introduction of reform. On the other hand, the public education system should first of all meet the interests of the State. Increasing international mobility should not result in a brain-drain. In order to avoid this, they need to be attractive employment conditions for highly qualified specialists.

The examination of the general picture of the reform as well as the diagnostics of the reform process in individual Ukrainian HEIs has shown us the specific aspects of the changes, and pointed out problems which are typical to the introduction of this process. The chance to see the reforms from someone else's viewpoint is an important step in the enhancement of and adjustment to the process. Therefore the present opinion poll could serve as a ground for obtaining a more general evaluation of the reforms at a particular higher education institution, and it could be used as a tool for selfdiagnosis.

\section{References:}

Bakirov, Vil S. 2006. "Knowledge Society" and Transformation of Higher Education. In Methodology, Theory and Practice of Sociologic Analysis of Modern Society. Collection of Scientific Studies, vol. 1, 352-357. Kharkov: Publishing House of Kharkov National University.

Barr, Robert B. and John Tagg. 1995. From Teaching to Learning: A New

Paradigm for Undergraduate Education. Change 27 (6): 12-25.

Beck, Ulrich. 2005. Risk Society. Towards a New Modernity. Thousand Oaks: Sage Publications.

Bourdieu, Pierre. 1967. Systems of Education and Systems of Thought. International Social Science Journal 19 (3): 338-358.

Castells, Manuel. 2000. End of Millenium, The Information Age: Economy, Society and Culture. Oxford: Blackwell Publishers.

Eco, Umberto. 2004. How to Make a Thesis. Moscow: KDU.

Habermas, Jürgen. 1987. The Idea of the University - Learning Processes. New German Critique 41: 3-22.

Mikheyeva, Oksana K. and A. Burego. 2008. Monitoring of the Reformation Process of Higher Education According to the Requirements of the Credit-Module System in Donetsk State University of Management. In Contemporary Social Problems within the Dimension of Sociology of Management: Collections of Scientific Studies of DonSUM, Vol. 9, 382392. Donetsk: DonSUM Eastern Publishing House. 